\title{
Correction to: Different localization of lysosomal-associated membrane protein 1 (LAMP1) in mammalian cultured cell lines
}

\author{
Kosuke Baba ${ }^{1}$. Sara Kuwada ${ }^{1}$ Ayaka Nakao ${ }^{1} \cdot{\text { Xuebing } \mathrm{Li}^{2} \cdot \text { Naoaki Okuda }^{1} \cdot \text { Ai Nishida }^{1} \cdot \text { Satoshi Mitsuda }}^{1}$.

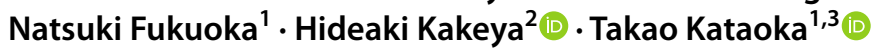

Published online: 7 July 2021

○) Springer-Verlag GmbH Germany, part of Springer Nature 2021

\section{Correction to: \\ Histochemistry and Cell Biology (2020) 153:199-213 \\ https://doi.org/10.1007/s00418-019-01842-z}

We used anti- $\beta$-actin antibody (2F3; Wako Pure Chemical Industries) and anti- $\beta$-actin antibody (AC- 15 ; SigmaAldrich) in Western blots in Fig. 5b and Fig. 5c, respectively. In May 2021, the FUJIFILM Wako Pure Chemical Corporation noticed us that $2 \mathrm{~F} 3$ antibody used in this study is reactive to $\gamma 1$-actin, but not $\beta$-actin. In a manner similar to $\beta$-actin, $\gamma 1$-actin is expressed broadly in human and mouse tissues. Consistent with this, the expression patterns of $\gamma 1$-actin and $\beta$-actin were similar in different culture cell lines (Fig. 5b, c). This change does not affect the interpretation of the results and conclusions. We apologize for any inconvenience caused by this correction.

The corrected text and Fig. 5 are provided below:

\section{Materials and methods}

\section{Western blotting}

The preparation of cell lysates was performed as described previously (Matsuda et al. 2014). Cell lysates (20 $\mu \mathrm{g})$ were

The original article can be found online at https://doi.org/10.1007/ s00418-019-01842-z.

Takao Kataoka

takao.kataoka@kit.ac.jp

1 Department of Applied Biology, Kyoto Institute of Technology, Matsugasaki, Sakyo-ku, Kyoto 606-8585, Japan

2 Department of System Chemotherapy and Molecular Sciences, Graduate School of Pharmaceutical Sciences, Kyoto University, Kyoto, Japan

3 The Center for Advanced Insect Research Promotion (CAIRP), Kyoto Institute of Technology, Kyoto, Japan digested with or without $250 \mathrm{U}$ of a peptide: N-glycosidase F (PNGase F; New England Biolabs, Ipswich, MA, USA) in a final volume of $20 \mu \mathrm{l}$ at $37^{\circ} \mathrm{C}$ for 1 or $1.5 \mathrm{~h}$. Proteins were separated by SDS-PAGE and transferred onto a $0.2-\mu \mathrm{m}$-thick ClearTrans ${ }^{\circledR}$ nitrocellulose membrane (FUJIFILM Wako Pure Chemical Corporation, Osaka, Japan). A rabbit antiLAMP1 antibody (L1418; $1 \mu \mathrm{g} / \mathrm{ml})$, rabbit anti-LAMP1 antibody (ab24170; $1 \mu \mathrm{g} / \mathrm{ml})$, mouse anti- $\gamma 1$-actin antibody (2F3; Wako Pure Chemical Industries; $0.1 \mu \mathrm{g} / \mathrm{ml}$ ), mouse anti- $\beta$-actin antibody (AC-15; Sigma-Aldrich, $0.48 \mu \mathrm{g} / \mathrm{ml}$ ), and horseradish peroxidase-conjugated anti-rabbit IgG and anti-mouse IgG antibodies (Jackson ImmunoResearch Laboratories, West Grove, PA, USA; each $0.16 \mu \mathrm{g} / \mathrm{ml}$ ) were used for Western blotting. Protein bands were analyzed by ImageQuant LAS 4000 mini (GE Healthcare, Piscataway, NJ, USA). The $\gamma 1$-actin monoclonal antibody (2F3) was raised against the synthetic peptide D(Ac)DDIAALVIDNGSGLC conjugated to keyhole limpet hemocyanin $(\mathrm{KLH})$, and was described to be reactive to $\gamma 1$-actin. The $\beta$-actin monoclonal antibody (AC-15) was raised against the synthetic peptide $\mathrm{D}(\mathrm{Ac})$ DDIAALVIDNFSGL conjugated to KLH, and was described to be reactive to $\beta$-actin derived from various species, including humans, rats, and mice. Anti- $\gamma 1$-actin antibody (2F3) and anti- $\beta$-actin antibody (AC-15) detected a single band around the 46- and 47-kDa protein markers, respectively, in human, rat, mouse, Chinese hamster, and golden hamster cell lysates. 
Fig. 5 N-Glycosylated and non-N-glycosylated forms of LAMP1 derived from the rat, mouse, human, golden hamster, and Chinese hamster were detected by two polyclonal anti-LAMP1 antibodies. a Structure of human LAMP1. Human LAMP1 is composed of a signal peptide (SP), luminal domain, transmembrane (TM) domain, and short cytoplasmic tail. The luminal domain has 18 consensus sequences for $\mathrm{N}$-glycosylation (filled circles). The anti-LAMP1 antibodies L1418 and ab24170 were raised against the 405-416 and 350-417 amino acid sequences of human LAMP1, respectively. $\mathbf{b}$ and $\mathbf{c}$ Cell lysates were prepared from NRK cells, BHK-21 (Lot. 5) cells, CHO-K1 cells, A549 cells, 293 cells, C2C12 cells, and YAC-1 cells. Cell lysates were digested with $(+)$ or without (-) PNGase F for $1 \mathrm{~h} \mathrm{(b)} \mathrm{and} 1.5 \mathrm{~h} \mathrm{(c).} \mathrm{Cell}$ lysates were then analyzed by Western blotting using a rabbit anti-LAMP1 antibody (L1418) (b) and anti-LAMP1 antibody (ab24170) (c), together with a mouse anti- $\gamma 1$-actin antibody (2F3) (b) and anti- $\beta$-actin antibody (AC-15) (c) as loading controls. Data were representative of at least three independent experiments a

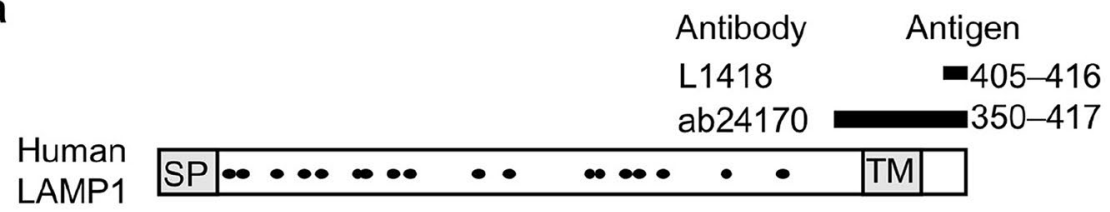

b

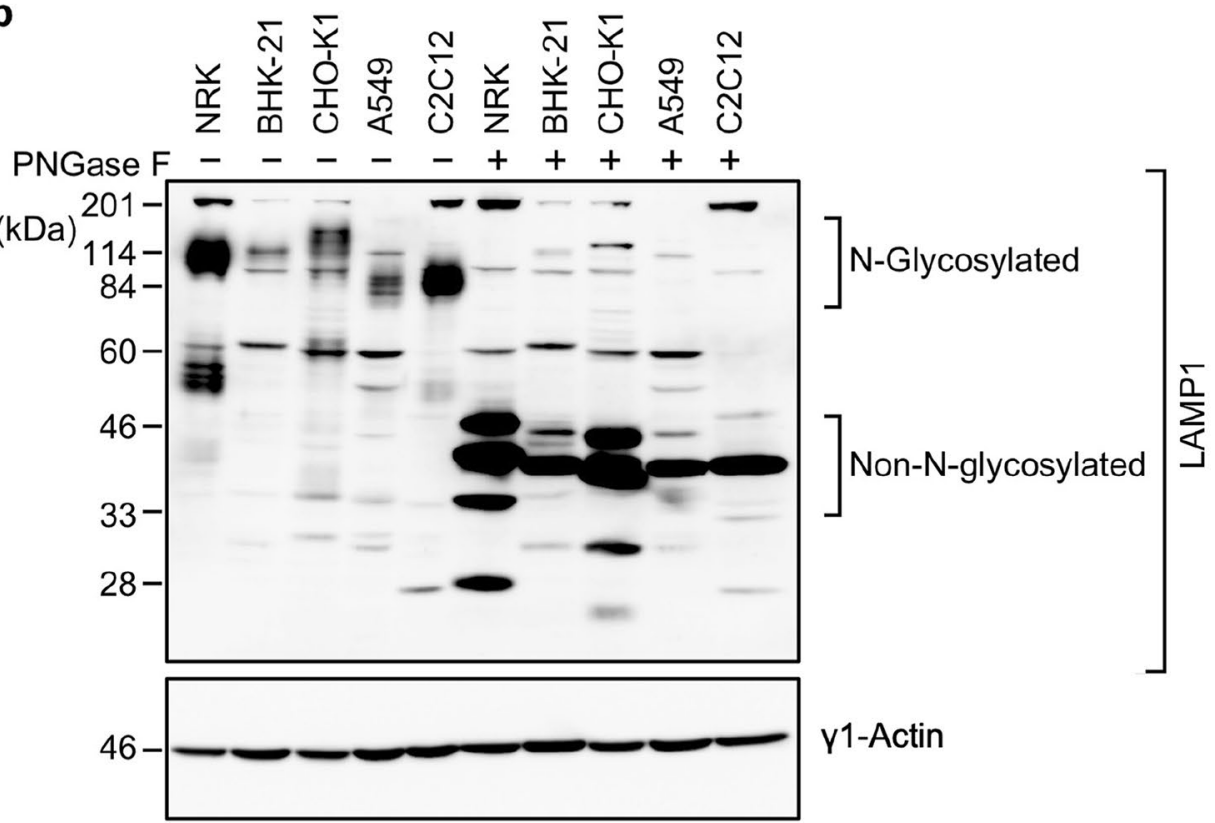

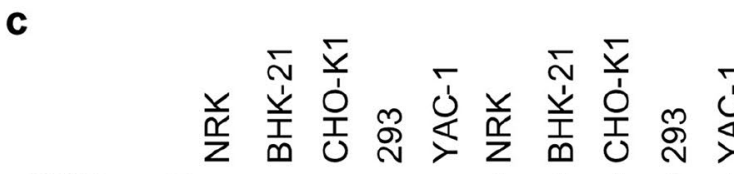

PNGase F - _ _ - + + + + (kDa)
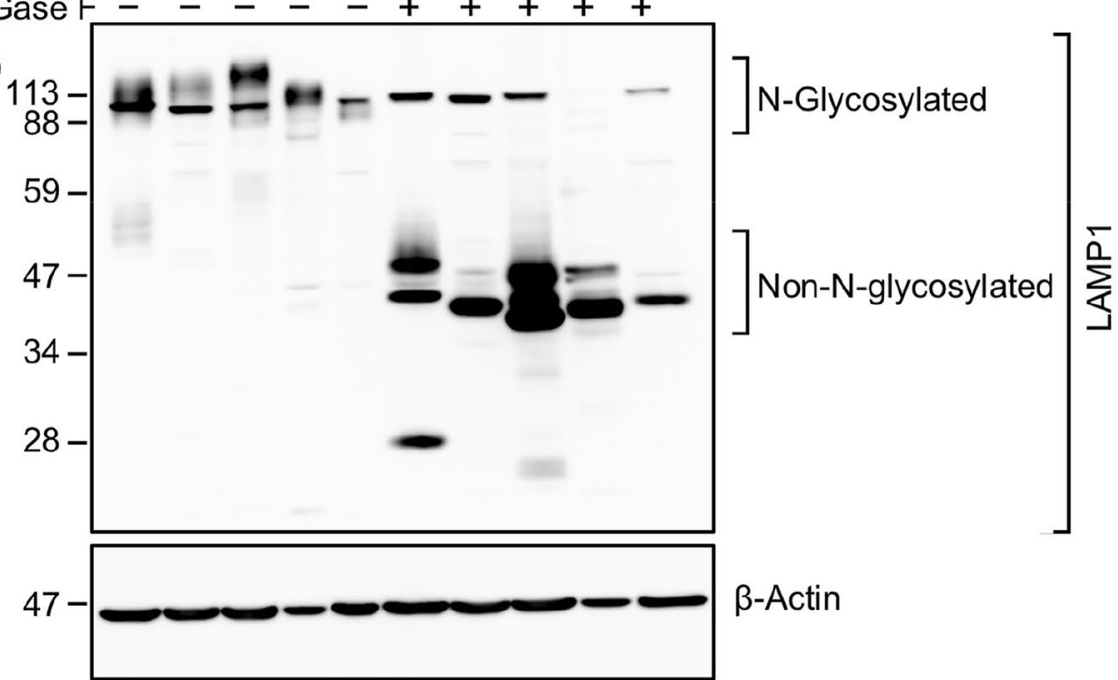

Publisher's Note Springer Nature remains neutral with regard to jurisdictional claims in published maps and institutional affiliations. 